\title{
Prevalence of Arm Lymphedema among Patients with Breast Cancer Surgery
}

\author{
Radha Acharya Pandey, Shilpa Shrestha
}

Kathmandu University School of Medical Sciences, Dhulikhel Hospital, Kathmandu University Hospital, Dhulikhel, Kavre, Nepal

\section{Correspondence \\ Ms Radha Acharya Pandey \\ Kathmandu University \\ School of Medical Sciences, \\ Dhulikhel Hospital, \\ Kathmandu University \\ Hospital, Dhulikhel, Kavre, \\ Nepal \\ E Mail: \\ radhapnd@yahoo.com \\ DOI: http:// \\ dx.doi.org/10.3126/ \\ jcmsn.v12i3.16016 \\ Article received: $\mathrm{July} 8^{\text {th }}$ 2016}

Article accepted: $\operatorname{Aug} 28^{\text {th }}$

2016

\begin{abstract}
Background \& Objectives: Lymphedema is a common complication of cancer therapeutics; its prevalence, treatment outcomes, and costs have been poorly defined. It is potentially debilitating condition in breast cancer survivors which negatively affects the quality of life. This study aims to assess the prevalence of arm lymphedema among patients with breast cancer surgery. Materials \& Methods: A cross-sectional study was conducted to assess the prevalence of arm lymphedema among the women with breast cancer surgery. Purposive sampling technique was used to collect the data from a sample of 66 women of selected hospitals. Data were collected through self constructed structured and semi structured interview based questionnaire which consisted socio demographic information and clinical related factors. Results: Among The overall prevalence of arm lymphedema was found to be seven $(10.6 \%)$ respondents among the study population. In this study, $41(62.1 \%)$ respondents were $<50$ years of age, $13(19.7 \%)$ had education of secondary level, $27(40.9 \%)$ had received radiation therapy, $63(95.5 \%)$ had no history of infection, $54(81.8 \%)$ had undergone modified radical mastectomy, and $56(84.8 \%)$ had involved lymph node resection. Statistically no any significant association was found between these variables. Conclusion: On the basis of the findings, this conclusion has been drawn that prevalence of arm lymphedema among patients with breast cancer surgery was low $(10.6 \%)$. Moreover no association was found between the prevalence of arm lymphedema, sociodemographic variables and clinical related factors.
\end{abstract}

Key words: Arm lymphedema; Breast cancer; Prevalence

Citation: Pandey RA, Shrestha S. Prevalence of Arm Lymphedema among Patients with Breast Cancer Surgery. JCMS Nepal. 2016;12(3):111-7.

\section{INTRODUCTION}

Breast cancer is one of the common and leading causes of cancer related death in females and account for twenty nine percentage of all cancers diagnosed each year worldwide. ${ }^{1}$ With the advent of multimodality treatment and early detection methods, there is an overall improvement in survival. With this transformation of the disease into a chronic condition the focus of attention is recently being directed towards late post treatment sequelae like lymphedema. ${ }^{2}$

Lymphedema is the buildup of excess protein-rich lymph fluid in body tissues due to lymphatic insufficiency or obstruction of lymphatic drainage back into the bloodstream. Upper extremity lymph edema is one of the most common complications after breast cancer surgery with a reported incidence of six to $30 \%{ }^{3}$

Patients treated for cancer have a lifetime increased risk of developing lymphedema as it can develop within days or after many years. ${ }^{4}$ Breast carcinoma is second most common malignancy among women in Nepal and is also still a killer carcinoma in our context. $^{5}$

Breast cancer survivors are at increased risk for the development of breast cancer-related lymphedema, chronic, debilitating, and disfiguring condition that is progressive and requires lifelong selfmanagement of symptoms. It has been reported that 
over $40 \%$ of the 2.5 million breasts cancer survivors in the United States (US) may meet the criteria for breast cancer related lymphedema during their lifetimes. As life expectancy improves for women with breast cancer, more women will be living with possible side effects of the treatment. Consequently, effective prevention and management of treatment sequels such as lymphedema that can impair function and quality of life in breast cancer survivors have taken on increasing importance. ${ }^{6}$

The American cancer society estimates that about one in eight (12\%) women in the United State will develop invasive breast cancer during their lifetime. $^{7}$ According to the data from Bisheshwor Prasad (B.P.) Koirala Memorial Cancer Hospital, the incidence of breast cancer patients is $10.5 \%$ in Nepal. $^{8}$

Arm lymphedema is highly prevalent in women who have undergone treatment for breast cancer which may produce psychological, physical and functional damage and also has a negative impact on social wellbeing, resulting in additional burdens for cancer survivors. Therefore, early detection and prevention of arm lymphedema can help to minimize the morbidity of this disease. Thus the study aims to assess the prevalence of arm lymph edema and the factors associated with it.

\section{MATERIALS AND METHODS}

A quantitative cross sectional study design was used to investigate the arm lymphedema of patients with breast cancer surgery using purposive sampling technique. Women who have completed 1 month after breast cancer surgery and absence of functional change in the affected limb before surgery were inclusion of the study. A total of 66 respondents, who met eligible criteria were interviewed face to face. Those women who had bilateral mastectomy have not included in this study. Data was collected using self-constructed structured and semi structured questions after extensive searched of many literatures. Validity of the instrument was established by thoroughly reviewing of the literature. Consulted with the research advisor and the expert of related topics were done. Discussion with colleagues and then pretesting was done. Questionnaire was prepared in English and then translated into Nepali with the help of expert in related field.

The data was collected by interview, clinical records and measuring arm circumference. A circumferential difference of $\geq 2 \mathrm{~cm}$ at any of the five points between the affected and non-affected arms was defined as arm lymphedema. These five points were hand (at the first and fifth metacarpal), wrist (the distal edge of the styloid process), $10 \mathrm{~cm}$ below elbow, and five and $15 \mathrm{~cm}$ above elbow.

Total time allocation for completion of the questionnaire was 10-15 minutes for each participant. Numbering was done to the filled up questionnaire and collected data was stored in the file to prevent loss and damage. The collected raw data were analyzed in SPSS 16 version for both descriptive and inferential statistics

\section{Ethical consideration}

Ethical approval was given by concerned authority of Bhaktapur Cancer Hospital and National Hospital and Cancer Research Centre. The informed consent of the participating patients was also obtained after having provided information with regard to the aim of the study and the confidentiality of the data collected. The participants were allowed to withdraw from the study at any time without giving reason and without fear.

\section{RESULTS}

Table 1 reveals that out of 66 respondents more than half i.e. $41(62.1 \%)$ of the respondents belonged to age group less than 50 years followed by $25(37.9 \%)$ of age group more than or equal to 50 years. Thirty five $(53 \%)$ respondents were illiterate whereas $31(47 \%)$ were literate in which $13(19.7 \%)$ of the respondents had secondary level of education. Majority i.e. $62(93.9 \%)$ of the respondents were married and $44(66.7 \%)$ of respondents were housewife followed by 15 $(22.7 \%)$ engaged in agriculture. Among 66 respondents, $38(57.6 \%)$ had normal BMI and 27 $(40.9 \%)$ were overweight.

Table 2 illustrates that out of 66 respondents, more than half of the respondents had the time interval of less than 6 months after surgery and $26(39.4 \%)$ had more than or equal to 6 months. All the respondents had received chemotherapy. Among the total respondents, $27(40.9 \%)$ had received radiation therapy and $29(43.9 \%)$ of the respondents had surgery in the dominant hand. Majority i.e. 63 $(95.5 \%)$ respondents didn't have history of infection in the wound site, while 54 (81.8\%) had undergone modified radical mastectomy. Among the total respondents $36(54.5 \%)$ had second stage of cancer while $21(31.8 \%)$ and $9(13.6 \%)$ had third and first stage of cancer respectively. Majority i.e. 56 
Table 1: Socio Demographic Information of the Respondents $\quad(n=66)$

$\begin{array}{ll}\text { Variables } & \text { Frequency }(\%) \\ \text { Age in completed years } & \\ <50 \text { years } & 41(62.1) \\ \geq 50 \text { years } & 25(37.9)\end{array}$

\section{Educational level}

\begin{tabular}{ll} 
Illiterate & $35(53)$ \\
\hline $\begin{array}{l}\text { Literate } \\
\quad \text { Primary education }\end{array}$ & $31(47)$ \\
\multicolumn{1}{c}{$\begin{array}{c}\text { Lower secondary } \\
\quad \text { education }\end{array}$} & $13(19.6)$ \\
$\quad \begin{array}{c}\text { Higher secondary and } \\
\text { above }\end{array}$ & $9(13.6)$ \\
Marital Status & \\
Married & $62(93.9)$ \\
Unmarried & $4(6.1)$ \\
Occupation & \\
Housewife & $44(66.7)$ \\
Agriculture & $15(22.7)$ \\
Business & $1(1.5)$ \\
Teaching & $3(4.5)$ \\
Institution & $2(3.0)$ \\
Tailor & $1(1.5)$ \\
BMI & $1(1.5)$ \\
$<18.5$ & $38(57.6)$ \\
$18.5-24.99$ & $27(40.9)$ \\
$25-29.99$ &
\end{tabular}

$(84.8 \%)$ of the respondents had undergone dissection of lymph node during their surgery. Table 3 displays that out of total respondents, seven $(10.6 \%)$ of them had developed arm lymphedema.

Out of all respondents six $(14.63 \%)$ of them $<50$ years and one $(4 \%)$ of $\geq 50$ years had arm lymphedema. Statistically there is no significant association between age and prevalence of arm lymphedema as $\mathrm{p}$ value is more than 0.05 i.e. 0.239 at $5 \%$ level of significance.

Out of total respondents four $(13 \%)$ and three $(8.6 \%)$ of literate and illiterate had arm lymphedema respectively. There is no association between prevalence of arm
Table 2: Clinical related factors of the Respondents $(n=66)$

$\begin{array}{ll}\text { Variables } & \text { Frequency (\%) } \\ \text { Time interval after surgery } & \\ <6 \text { months } & 40(60.6) \\ \geq 6 \text { months } & 26(39.4)\end{array}$

\section{Chemotherapy}

Yes

$66(100)$

No

0

$\begin{array}{ll}\text { Radiation } & \\ \text { Yes } & 27(40.9) \\ \text { No } & 39(59.1)\end{array}$

Involvement of Dominant hand

$\begin{array}{ll}\text { Yes } & 29(43.9) \\ \text { No } & 37(56.1)\end{array}$

$\begin{array}{ll}\text { Infection } & \\ \text { Yes } & 3(4.5) \\ \text { No } & 63(95.5)\end{array}$

Types of surgery

$\begin{array}{ll}\text { Breast conservative surgery } & 12(18.2) \\ \text { Modified radical mastectomy } & 54(81.8)\end{array}$

$\begin{array}{ll}\text { Stage of disease } & \\ \text { Stage } 1 & 9(13.6) \\ \text { Stage } 2 & 36(54.5) \\ \text { Stage } 3 & 21(31.8)\end{array}$

\begin{tabular}{ll} 
Involvement of lymph node \\
\hline Yes & $56(84.8)$ \\
\hline No & $10(15.2)$
\end{tabular}

Table 3: Prevalence of Arm Lymphedema of Respondents $(n=66)$

Arm lymphedema Frequency (\%)

$\begin{array}{ll}\text { Absent } & 59(89.4) \\ \text { Present } & 7(10.6)\end{array}$

lymphedema and level of education as $\mathrm{p}$ value is 0.698 .

Similarly, there was no significant different between marital status, BMI and prevalence of arm lymphedema as $p$ value is more than 0.05 at $5 \%$ level of significance (Table 4). Table 5 shows that out of total respondents, only four $(10 \%)$ respondents developed arm lymphedema within six months and 
Table 4: Association between Prevalence of Arm lymphedema and Selected Socio Demographic Variables $(n=66)$

\begin{tabular}{|c|c|c|c|c|}
\hline \multirow{2}{*}{$\begin{array}{l}\text { Variables } \\
\text { Age group }\end{array}$} & \multicolumn{2}{|c|}{ Arm lymphedema } & \multirow[b]{2}{*}{ Total } & \multirow[b]{2}{*}{$P$ value } \\
\hline & $\begin{array}{l}\text { Absent } \\
\text { No.(\%) }\end{array}$ & $\begin{array}{l}\text { Present } \\
\text { No.(\%) }\end{array}$ & & \\
\hline$<50$ years & $35(85.4 \%)$ & $6(14.6 \%)$ & $41(62.1 \%)$ & 0.239 \\
\hline$\geq 50$ years & $24(96 \%)$ & $1(4 \%)$ & $25(37.9 \%)$ & \\
\hline \multicolumn{5}{|c|}{ Education status } \\
\hline Illiterate & $32(91.4 \%)$ & $3(8.6 \%)$ & $35(53 \%)$ & 0.698 \\
\hline Literate & $27(87 \%)$ & $4(13 \%)$ & $31(47 \%)$ & \\
\hline \multicolumn{5}{|l|}{ Marital Status } \\
\hline Married & $56(90.3 \%)$ & $6(9.7 \%)$ & $62(94 \%)$ & 0.369 \\
\hline Unmarried & $3(75 \%)$ & $1(25 \%)$ & $4(6 \%)$ & \\
\hline \multicolumn{5}{|l|}{ BMI } \\
\hline Normal & $35(92.1 \%)$ & $3(7.9 \%)$ & $38(57.6 \%)$ & 0.446 \\
\hline Malnourished & $24(85.7 \%)$ & $4(14.3 \%)$ & $28(42.4 \%)$ & \\
\hline
\end{tabular}

Table 5: Association between Prevalence of Arm Lymphedema and Selected Clinical Related Factors $(n=66)$

\begin{tabular}{|c|c|c|c|c|}
\hline \multirow{2}{*}{ Variables } & \multicolumn{2}{|c|}{ Arm lymphedema } & \multirow{2}{*}{ Total } & \multirow{2}{*}{$P$ value } \\
\hline & Absent & Present & & \\
\hline \multicolumn{5}{|l|}{ Time interval after surgery } \\
\hline$<6$ months & $36(90 \%)$ & $4(10 \%)$ & $40(60.6)$ & \multirow{2}{*}{1.0} \\
\hline$\geq 6$ months & $23(88.5 \%)$ & $3(11.5 \%)$ & $26(39.4)$ & \\
\hline \multicolumn{5}{|l|}{ Radiation therapy } \\
\hline Yes & $24(88.9 \%)$ & $3(11.1 \%)$ & $27(40.9)$ & \multirow{2}{*}{1.0} \\
\hline No & $35(89.7 \%)$ & $4(10.3 \%)$ & $39(59.1)$ & \\
\hline \multicolumn{5}{|c|}{ Involvement of dominant hand } \\
\hline Yes & $24(82.8 \%)$ & $5(17.2 \%)$ & $29(43.9)$ & \multirow{2}{*}{0.226} \\
\hline No & $35(94.6 \%)$ & $2(5.4 \%)$ & $37(56.1)$ & \\
\hline \multicolumn{5}{|l|}{ History of infection } \\
\hline Yes & $2(66.7 \%)$ & $1(33.3 \%)$ & $3(4.5)$ & \multirow{2}{*}{0.29} \\
\hline No & $57(90.5 \%)$ & $6(9.5 \%)$ & $63(95.5)$ & \\
\hline \multicolumn{5}{|l|}{ Type of Surgery } \\
\hline Breast conservative surgery & $10(83.3 \%)$ & $2(16.7 \%)$ & $12(18.2 \%)$ & \multirow{2}{*}{0.6} \\
\hline MRM & $49(90.7 \%)$ & $5(9.3 \%)$ & $54(81.8 \%)$ & \\
\hline \multicolumn{5}{|l|}{ Involvement of lymph node } \\
\hline Yes & $50(87.7 \%)$ & $7(12.3 \%)$ & $57(86.4 \%)$ & \multirow{2}{*}{0.581} \\
\hline No & $9(100 \%)$ & 0 & $9(13.6 \%)$ & \\
\hline
\end{tabular}


three $(11.5 \%)$ respondents developed arm lymphedema after 6 months of surgery. Statistically there is no significant association between prevalence of arm lymphedema and time interval after surgery as $p$ value is 1.0 at $5 \%$ level of significance.

Likewise, three (11.1\%) of respondents had developed arm lymphedema those who were received radiation therapy. Statistically there is also no significant association between these variables. Similarly there was no significant relation between involvement dominant hand, lymph node, type of surgery and history of infection with the prevalence of arm lymphedema.

\section{DISCUSSION}

This study was conducted to identify the prevalence of arm lymphedema and its associated factors among patients with breast cancer surgery. This discussion chapter deals with discussion of the major findings of this study with the findings of similar study done before.

In present study the prevalence of patients with arm lymphedema after breast cancer surgery was seven. A study conducted by Svs D et al.2 in India showed the prevalence of arm lymphedema as $33.5 \%$ and Bergmann et al. 9 in Brazil showed $20.8 \%$ in women treated for breast cancer respectively. The prevalence of arm lymphedema varies from 9 to $40 \%$ as reported by other studies.2, 3, 11, 12, 14, 16 This wide variation in prevalence might be due to lack of consensus regarding method of assessment and timing of assessment for arm lymphedema.

In the present study there is no significant association between age and arm lymphedema which is similar to the study of Bermann A.et al.9, Paiva D.et al.10 and yen et al.17 But in the study done in Iran 3and Australia11 revealed that arm lymphedema was more prevalent in higher age of women.

Although four of the total respondents with arm lymphedema were educated in the current study but statistically there was no significant association between prevalence of arm lymphedema and education level of respondents. A study conducted in Iran have shown that low level of education is associated with risk of arm lymphedema.3

In the present study there is no significant association between marital status and arm lymphedema which is similar to the study conducted in Iran by Haghighat Shahpar et al.3 while paskett et al.21 have shown that the risk of arm lymphedema among married women was 1.36 times higher than risk for unmarried women.

A study in Iran 3 showed that every increase of $1 \mathrm{~kg} /$ $\mathrm{m} 2$ in BMI may increase the risk of arm lymphedema while study in Brazil resulted that obesity is associated with the increase risk of arm lymphedema.9 However this present study showed no any significant association between BMI and arm lymphedema as similar to the study of Togawa et al.15 and Geller et al.12 which also showed no association between change in BMI and risk of breast cancer related arm lymphedema.

In the present study there is no significant association between arm lymphedema and time interval after surgery which is similar to the study conducted by Bermann A. et al.9 But in the study done in Iran3 showed that the increase of every 1 month after surgery increases risk of arm lymphedema whereas the study done by Paiva $\mathrm{D}$ et al.10 showed that women who have undergone surgery for more than 5 years previously had a 9.7 times higher compared with those who have undergone surgery less than 5 years.

In the study conducted in Taiwan resulted that Radiation was significantly associated with lymphedema in the MRM group, but not in the breast conserving surgery group.13 A study done in India 2 and in Brazil 9 showed that post-operative radiation was significant associated with increased risk of arm lymphedema respectively which was contradict to the current study.

In the study of Australia 11 revealed that being treated on dominant hand increases the risk of arm lymphedema. Likewise the study done in Denmark 19 showed no evidence linking the factors i.e. operation on the dominant hand with increased risk for developing arm lymphedema which was similar to the current study.

The findings of the present study contradicts to findings of the studies done in Iran 3, Brazil9 and France15 which have shown that the history of infection is significantly associated with risk of arm lymphedema.

The present study showed no significant association between the prevalence of arm lymphedema and type of surgery which contradicts the studies done in Taiwan13, USA12, and Vermont20 which have shown significant association between arm lymphedema and types of surgery.

The present study showed no significant association between arm lymphedema and involvement of 
lymph node which is similar to the study conducted in Taiwan13. In the study done in Iran3 showed that each number increase in the lymph node involvement increases the prevalence of arm lymphedema where as in the study done in Turkey 14, California 18 and Vermont 13, 20 showed that women who have more lymph nodes removed are at increased risk.

\section{CONCLUSION}

On the basis of the findings and discussion, this conclusion has been drawn that prevalence of arm lymphedema among patients with breast cancer surgery of selected hospitals was $10.6 \%$. Moreover no association was found between the socio demographic variables and arm lymphedema. There is no significant association was found between treatment related factors and arm lymph edema.

\section{Acknowledgements}

The authors thank the participants who were included in this study for their kind co-operation and willingness to help us in the research work.

Recommendations

In the present study, the small sample size could have affected the prevalence rate of arm lymphedema and its association with other variables. Thus further research should be conducted with large sample size.

\section{Limitations}

Data was collected through structured and semi structured questionnaire thus, in depth information could not be collected due to the use of maximum number of close ended questions. Findings may not be generalized to the whole population because of small sample size and use of non-probability sampling technique. As association between variables is measured using fisher's exact test thus other statistical test can also be used in order to find significant association between variables.

\section{Implication}

Finding of study might provide the interested personnel with some basic information to conduct future research on related topic. This study helps to find out prevalence of arm lymphedema among patients with breast cancer surgery. The finding of this study will help the health personnel or care provider to prevent the arm lymphedema among patients with breast cancer surgery.

\section{REFERENCES}

1. Acharya SC, Jha AK, Manandhar T. Clinical Profile of Patients Presenting with Breast Cancer in Nepal. Kathmandu Univ Med J. 2012;39:3-7.

2. Svs D, Ray S, Gk R, Nk S, Kar M, Asthana S, Raina V. Prevalence and Risk Factors for Development of Lymphedema following Breast Cancer Treatment. All India Institute of Medical Sciences. 2004;41:8-12.

3. Shahpar H, Atieh A, Maryam A, Fatemeh HS, Massoome N, Mandana E, Esmaeil AM. Risk Factors of Lymph Edema in Breast Cancer Patients. International Journal of Breast Cancer. 2013;17-21. DOI: $10.1155 / 2013 / 641818$.

4. Prevention of clinical lymphedema after cancer treatment : Early detection and risk reduction. A guide for Health Professional. National Cancer control programme, 2015.Availablefrom:https://www.hse.ie//cancer/.../ lymphoedema $\% 20$ booklet $\% 20$ for $\% 20$ healthcare.

5. Pradhan GB, Shrestha R, Shrestha S, Khadka P, Bhattachan CL. Outcome analysis of breast cancer patients treated at Nepal Medical College. Nepal Medical college Journal. 2012;93-5. PMID:23671954.

6. Ostby PL, Armer JM , Dale PS, Loo MJ Van, Wilbanks CL, Stewart BR. Surveillance Recommendations in Reducing Risk of and Optimally Managing Breast Cancer-Related Lymphedema. Journal of Personalized Medicine. 2014;424-47. DOI: 10.3390/ jpm4030424. PMID:25563360.

7. American cancer society. Cancer facts and figures. Available from: www.oralcancerfoundation.org/facts/pdf/ Us_Cancer_Facts.pdf by BCI Situ - 2015.

8. Annual Report of B.P.Koirala Memorial 2014, Bharatpur, Chitwan

9. Bergmann A, Koifman RJ, Koifman S, Ribeiro MJP, Mattos IE. Upper limb lymphedema following breast cancer surgery: prevalence and associated factors. Lymphology. 2007;96-106.

10. Paiva DMF, Rodrigues VO, Cesca MG, Palma PV, Leite G . Prevalence of lymphedema in women undergoing treatment for breast cancer in a referral center in southeastern Brazil. BMC Women's Health. 2013;13:1. DOI: 10.1186/1472-6874-13-6. PMID:23406386.

11. Hayes SC, Janda M, Cornish B, Battistutta D, Newman B. Lymphedema After Breast Cancer: Incidence, Risk Factors and Effect on Upper Body Function. Journal of clinical oncology. 2008;26. DOI: 10.1200/jco.2007.14.4899.

12. Geller BM, Vacek PM, Brien PO. Factors Associated with Arm Swelling after Breast Cancer Surgery. Journal of women's health. 2003;12. DOI: 10.1089/154099903770948159.

13. Liao S, Lee $Y$, Chen S, Kuo S. Incidence and Risk Factors Analysis of Lymphedema. Tw j phys med rehabil. 2009;217-25.

14. Kibar S, Aras MD, Delialioglu SU, Koseoglu BF. Risk Factors Associated with Lymphedema and its Prevalence in Breast Cancer Patients after Level 3 Axillary Lymph Node Dissection. Turk J Phys Med Rehab. 2015;36-44.

15. Togawa K, Ma H, Sullivan J, Neuhouser ML, Imayama I, Baumgartner KB, Bernstein L. Risk factors for selfreported arm lymphedema among female breast cancer survivors. 2014;1-15.

16. Vignes S, Arrault M, Dupuy A. Factors associated 
with increased breast cancer- related lymphedema . Acta Oncologica. 2007;46:1138-42.

10.1080/02841860701403020. PMID:17851861.

17. Goffman TE, Laronga C, Wilson L, Elkins D. Lymphedema of the Arm and Breast in Irradiated Breast Cancer Patients: Risks in an Era of Dramatically Changing Axillary Surgery. The breast journal. 2010;10:17.

18. Mortimer PS, Bates DO, Brassington HD, Stanton AWB, Strachan DP, Levick, JR. The prevalence of arm edema following treatment for breast cancer. Lancet. 1996;37780.

19. Tsai R, Dennis L, Lynch C, Snetselaar L, Zamba G, ScottConner. The risk of developing arm lymphedema among breast cancer survivors. A meta-analysis of treatment factors. Ann surgical oncology 2009; 1959-72. DOI: 10.1245/s10434-009-0452-2. PMID:19365624.

20. Kocak Z, Overgaard J. Risk factors of arm lymphedema in breast cancer patient. Danish Cancer Society. Acta Oncology. 2000;39:389-92. 10.1080/028418600750013168. PMID:10987236.

21. Paskett ED, Paskett MJ, Naughton TP, McCoy LD, Case JM. Abbott. The epidemiology of arm and hand swelling in premenopausal breast cancer survivors. Cancer Epidemiology Biomarkers and Prevention. 2007;16:77582 . DOI: $\quad 10.1158 / 1055-9965 . E P I-06-0168$. PMID: 17416770. 